\title{
Imaging in patients with breast implants-results of the First International Breast (Implant) Conference 2009
}

\author{
Frank Stöblen • Mahdi Rezai • Sherko Kümmel
}

Received: 16 March 2010/Accepted: 8 April 2010/Published online: 4 May 2010

(C) European Society of Radiology 2010

\begin{abstract}
Background The First International Breast (Implant) Conference was held by the $\operatorname{EAoS}^{\circledR}$ (European Academy of Senology) in cooperation with the German Society of Senology during its 29th annual meeting in Düsseldorf, Germany, on 13 June 2009.

Methods It was performed as a whole-day interactive workshop in which the standards of implant surgery within reconstructive and aesthetic breast surgery were discussed and defined by telecommunication dialogue voting.

Results This article describes the conference results concerning pre- and post-procedural imaging in patients with breast implants. Both before and after augmentation, imaging is mandatory and provides essential information concerning tissue and implant integrity. Whereas mammography is the first-line method before surgery, ultrasound is the mainstay of post-procedural imaging. Cancer screening
\end{abstract}

\section{F. Stöblen}

Diavero Breast Diagnosis Center,

Heidbergweg 22-24,

45257 Essen, Germany

\section{Rezai}

Breast Center, Luisenkrankenhaus, Degerstr. 8,

40235 Düsseldorf, Germany

\section{S. Kümmel}

Breast Center, Kliniken Essen-Mitte,

Henricistr. 92,

45136 Essen, Germany

\section{F. Stöblen $(\bowtie)$}

Diavero-Diagnosezentrum,

Heidbergweg 22 - 24,

45257 Essen, Germany

e-mail: dr.stoeblen@diavero.de in augmented breasts generally follows the same guidelines as for non-augmented breasts.

Conclusion Whereas agreement about the indications for mammographical and sonographical evaluations is largely unanimous, there was substantial disagreement as far as the application of magnetic resonance imaging is concerned. There is an obvious demand for an evidence-based evaluation of this modality and the implementation of appropriate guidelines.

Keywords Breast . Implant · Mammography ·

Magnetic resonance imaging $\cdot$ Ultrasound

\section{Introduction}

Breast implant insertion has evolved as a largely established and accepted modality for reconstruction after mastectomy, correction of congenital malformations and cosmetic augmentation of the breast [1]. The procedural volume of alloplastic breast implant reconstruction and augmentation is high, and it will further increase in the future. According to benchmark studies of the West German Breast Center [2], the mastectomy rate in Germany is currently about $35 \%$, resulting in about $15,000-25,000$ mastectomies per year. In addition to this figure, there is an ever-increasing demand for cosmetic breast implantation that has led to a dramatic rise in procedure numbers in the past 2 decades [3, 4]. To date, breast augmentation with single lumen silicone implantscurrently the 'gold standard' of augmentation - is the single most common cosmetic procedure in the UK [5].

There are a number of issues that may require diagnostic imaging in patients with breast implants:

- Regular screening mammography 
- Additional imaging for BI-RADS 0, III, IV and V lesions

- Interventional biopsy

- Specific implant-related complications such as abnormal immune response or connective tissue diseases [6] and implant-associated tumors [7]

- Implant leakage or rupture [8]

Patients with breast implants present the radiologist with specific challenges, such as the identification and distinction of implant and breast tissue, diagnosis of implant defects and implant-related complications as well as diagnosis and follow-up of unrelated breast diseases such as mastitis or breast cancer [9]. The fact that an increased mortality due to malignant disease has been described among patients with breast implants [10] may indicate specific diagnostic difficulties, and indeed a decreased sensitivity of mammography in patients with silicone implants has been described [11].

Whereas this indicates the necessity of a differential diagnostic approach to breast imaging in patients with implants - and quite likely a more central role for magnetic resonance imaging - there are currently no widely accepted guidelines. Therefore, interactive consensus decisions were sought.

\section{Consensus decisions of the First International Breast (Implant) Conference 2009, Düsseldorf}

The expert panel consisted of 26 invited renowned experts from 5 countries (Germany, $n=20$; USA, $n=2$; Austria, $n=$ 2; $\mathrm{UK}, \mathrm{n}=1$; Italy, $\mathrm{n}=1$ ), including one of the pioneers of breast implantology (Dr. Thomas Biggs, Houston), the director of one of the busiest centers (Dr. Brian Kinney, Los Angeles) and the entire European panel of senior breast augmentation surgeons.

The consensus decisions were considered after a presentation of the best available evidence on each issue, a fullday discussion thereafter and a 2-day workshop focussing on the topic.

Decisions were made by means of telecommunication dialogue (TED) voting, i.e. each participant pushed the appropriate one of three buttons on a remote control device after a question was projected on-screen.

The conference decisions concerning imaging in patients before implant insertion or with implants, respectively, are displayed in Table 1.

Imaging before implant insertion

In general, a majority of attendees considered imaging before breast implantation as a necessity [except for very few exceptions, e.g., in very young women $(<25$ years $)$ without specific risk factors], and bidirectional mammography in combination with ultrasound is the preferred modality. There are several reasons to recommend some form of imaging before breast augmentation, with the possibility of opportunistic cancer detection being just one of them. The other key reasons that make breast imaging before augmentation practically mandatory are

- exclusion of suspicious lesions prior to surgery and

- diagnosis and documentation of pre-existing tissue alterations such as microcalcifications, etc.

Even if the latter are no reason for immediate further diagnostic and/or therapeutic measures, the documentation may be of crucial clinical-and forensic-importance if and when malignant lesions intercurrently occur in the augmented breast [12].

The general diagnostic properties of mammography and ultrasound determine that both methods should be employed in this order, just as in breast cancer screening. Sophisticated MR imaging and CAD calculation of implant size and shape [13] are currently uncommon; MRI is only employed by $9 \%$, but may become more important in the future.

Imaging after implant breast reconstruction following mastectomy

After mastectomy, the reconstructed breast is mostly examined by ultrasound (90\%), whereas MRI (42\%) and especially mammography (9\%) are substantially less frequently recommended. This preference is quite obvious and mainly dictated by the anatomical circumstances after mastectomy where both MRI and mammography are impractical because of the lack of mammary gland tissue.

Imaging after implant breast augmentation

After breast augmentation, imaging as such was stipulated unanimously, and there are two main and equally important indications for this: Diagnostic workup of possible implant rupture and ongoing breast cancer screening and diagnosis in implant-bearing patients. In general, ultrasound and-to a somewhat lesser extent-mammography were named as the methods of choice. Once again, MRI played an almost negligible role.

This opinion is well in line with the diagnostic requirements in patients after breast augmentation: The major specific complication is intra- or extra-capsular implant rupture, which occurs in up to $50 \%$ of women with augmented breasts within 12 years [14]. Studies on newer 
Table 1 Conference decisions on imaging in breast implantology (percentage of votes)

\begin{tabular}{|c|c|c|c|}
\hline \multirow[b]{2}{*}{ Question } & \multicolumn{3}{|c|}{ Percentage of votes } \\
\hline & 'Yes' & 'No' & 'Rarely' \\
\hline Should diagnostic imaging be performed before implant insertion without prior disease? & 77 & 15 & 8 \\
\hline Mammography, always bidirectional & 92 & 4 & 4 \\
\hline Mammography and mammasonography & 81 & 15 & 4 \\
\hline Magnetic resonance (MR) mammography & 8 & 77 & 15 \\
\hline Which diagnostic procedure do you recommend after implant reconstruction following mastectomy? Mammography? & 15 & 85 & 0 \\
\hline Which diagnostic procedure do you recommend after implant reconstruction following mastectomy? Sonography? & 92 & 8 & 0 \\
\hline \multicolumn{4}{|l|}{ Which diagnostic procedure do you recommend after implant reconstruction following mastectomy? } \\
\hline Magnetic resonance imaging (MRI)? & 42 & 15 & 42 \\
\hline \multicolumn{4}{|l|}{ Which diagnostic procedure do you recommend after augmentation with implants? } \\
\hline Mammography? & 77 & 15 & 8 \\
\hline \multicolumn{4}{|l|}{ Which diagnostic procedure do you recommend after augmentation with implants? } \\
\hline Sonography? & 92 & 8 & 0 \\
\hline \multicolumn{4}{|l|}{ Which diagnostic procedure do you recommend after augmentation with implants? } \\
\hline MRI? & 4 & 27 & 69 \\
\hline Can interventional biopsies be performed on implant patients? & 85 & 0 & 15 \\
\hline How would you perform a biopsy? Always open? & 12 & 62 & 27 \\
\hline Do you perform breast MRI after implant insertion in case of leakage without contrast medium? & 42 & 50 & 8 \\
\hline Is MRI critical for differential diagnosis of focal diagnostic findings after implant insertion? & 62 & 27 & 12 \\
\hline ...Upon leakage suspicion with contrast media? & 54 & 46 & 0 \\
\hline ...Upon leakage suspicion without contrast media? & 38 & 62 & 0 \\
\hline ...Upon tumor suspicion? & 81 & 19 & 0 \\
\hline \multicolumn{4}{|l|}{...In the case of palpation findings when sonography } \\
\hline and mammography are without pathological findings? & 46 & 54 & 0 \\
\hline
\end{tabular}

"third generation" implants suggest a lower failure rate of about $15 \%$ within 10 years [15], but considering the high (and increasing) number of women with implants, rupture must be considered a frequent condition. Implant rupture has well-defined and discernible sonographic features, i.e. the classical "snowstorm" appearance with dense acoustic shadowing [16]. A completely negative ultrasound examination has a very high predictive value for implant integrity [17], limiting the application of mammography or MRI to sonographically suspicious cases [5].

Although ultrasound diagnosis of implant failure is basically feasible, MRI evaluation is frequently recommended [16] and may become more important in the future [9, 18]. Presently, MRI is recommended in the diagnostic workup of clinically or sonographically suspicious cases, but not in asymptomatic women without previous conventional imaging [19], and an evidence-based assessment of its superiority over sonography in terms of diagnostic accuracy would be required to justify the general recommendation of the substantially more expensive MRI.

The second important issue in post-implant imaging is breast cancer screening and diagnosis. The suspected relationship between breast implants and cancer has essentially been disproved, but considering the high number of women with implants, cancer diagnosis in the augmented breast is a major issue [15, 20]. The mainstay of tumor screening and diagnosis in the augmented breast is - just as in non-operated patientsmammography and ultrasound in that order [22]; however, the sensitivity of both methods for cancer detection may be reduced in augmented breasts [11, 21], and patients ought to be informed of this fact before they undergo surgery. Therefore, the re-evaluation with MRI-which is discussed elsewhere in this paper-may become more important in augmented breasts, but currently the literature provides no sufficient evidence for its recommendation [21].

Three-dimensional ultrasound may become a basis of contemporary postoperative breast implant evaluation, thus providing a combination of medical diagnosis and aesthetic assessment for which so far only a few relatively demanding methods are available [23-25]; however, there is presently no evidence of this application of available breast scanner systems. 
Interventional biopsies in patients with breast implants

A substantial majority considered interventional biopsies in the augmented breast basically feasible and would only occasionally and upon necessity resort to open procedures. Since implants present very well on sonography and other imaging modalities, a decline in the number of interventional biopsies would hardly be justified. However, an interventional core needle biopsy has to be performed with particular care in order to avoid iatrogenic implant rupture [22].

\section{Application of MRI after implant insertion}

The value of MRI after breast augmentation is the one issue of substantial controversy. Almost regardless of the respective application, the number of votes for and against MRI in the panel discussion were equal. The only situation where most participants agreed about MRI making sense was a suspicion of tumor in the augmented breast, and this view is in accordance with the literature [e.g., 9, 18, 19, 26]. However, MRI is currently considered to be a secondline method to be applied after mammography has yielded a suspicious result that could not be verified or falsified by ultrasound examination or in cases of peri-implant positivity at clinical examination with inconclusive results of conventional imaging $[19,22]$. The same applies to the diagnosis of implant rupture where the value of MRI is undeniable, but its application limited to cases with inconclusive results of conventional imaging $[5,9,26$, 27]. Presently, the literature provides no evidence for the recommendation of MRI for screening purposes in patients with augmented breasts as given by the US Food and Drug Administration [28].

\section{Conclusions}

1. Before breast augmentation, imaging is strongly recommended for most women. It will mainly follow the same guidelines as in routine mammography screening, i.e. mammography followed by ultrasound if necessary. Findings that don't require immediate diagnostic or therapeutic action should be thoroughly documented.

2. Following augmentation after mastectomy, imaging is also a necessity, but ultrasound is the method of choice due to morphological and practical considerations.

3. The follow-up of previously healthy augmented breasts is guided by two rationales: diagnosis of complications (i.e., mainly rupture) and cancer screening. For the former, ultrasound examination is the current method of choice, whereas cancer screening in augmented breasts requires mammography.
4. Interventional biopsies in augmented breasts can and should be performed under more or less the same guidelines as in non-augmented breasts.

5. The role of MRI in the evaluation of breast implantbearing patients is possibly emerging, but presently controversial. Controlled trials with high methodological standards will be required to better define its specific values and to implement evidence-based guidelines; however, sonography and mammography still provide a very satisfactory basis.

Acknowledgements The conference took place on 13 June 132009 at CCD Stadthalle, Congress Center, Düsseldorf, Rotterdamer Straße 144, 40474 Düsseldorf, Germany. The conference language was English, and simultaneous translation to German was available on demand.

The participants in the conference are listed below (in alphabetical order):

Dr. Thomas Biggs, St. Joseph Hospital Houston, USA; PD Dr. Ingo Bauerfeind, Breast Center, Klinikum Landshut, Germany; Prof. Dr. Jens-Uwe Blohmer, Breast Center, Sankt Gertrauden-Krankenhaus Berlin, Germany; Dr. Klaus Brunnert, Breast Center, Klinikum Osnabrück, Germany; Prof. Dr. Dr. h.c. Serban-Dan Costa, Breast Center, University Hospital Magdeburg, Germany, Prof. Dr. Peter Dall, Breast Center, Klinikum Lüneburg, Germany; Dr. Mahmoud Danaei, Breast Center, Marienhospital Aachen, Germany; Dr. Maren Darsow, Breast Center, Luisenkrankenhaus Düsseldorf, Germany; Dr. Holger Dieterich, Breast Center, Krankenhaus Rheinfelden, Germany; Prof. Dr. Andree Faridi, Breast Center, University Hospital Aachen, Germany; Dr. Daphne Gschwantler-Kaulich, Breast Center, University Hospital Vienna, Austria; Dr. Volker Heyl, Breast Center, Asklepios Paulinen Klinik Wiesbaden, Germany; Prof. Dr. Wolfgang Janni, Department of Gynaecology and Obstetrics, University Hospital Düsseldorf, Germany; Dr. Brian Kinney, Olympia Medical Center, St. John's Hospital and Health Center and Cedars-Sinai Medical Center, Los Angeles, USA; PD Dr. Stefan Krämer, Brustambulanz Düsseldorf, Germany; PD Dr. Sherko Kümmel, Department of Gynaecology and Obstetrics, University Hospital Duisburg-Essen, Germany; Dr. Mario Marx, Breast Center East Saxonia, Görlitz, Germany; Prof. Dr. Dr. Bernd-Rudolf Muck, Breast Center NorthRhine, Evang. Krankenhaus Bethesda Mönchengladbach, Germany; Dr. Carolin Nestle-Krämling, Breast Center, University Hospital Düsseldorf, Germany; Dr. Stefan Paepke, Breast Center, University Hospital Charité, Berlin, Germany; Dr. Alberto Peek, Breast Center Vogtareuth, Germany; Dr. Mahdi Rezai (Scientific Chairman), European Academy of Senology, $\left(\mathrm{EAoS}^{\circledR}\right)$, Brustzentrum am Luisenkrankenhaus Düsseldorf, Germany; Dr. Mario Rietjens, European Institute of Oncology (EIO), Milano, Italy; Dr. David Ross, Guy's, St Thomas' Hospitals and Kings College Hospital, London, UK; Prof. Dr. Christian F. Singer, Breast\&Health Treatment Center, Vienna, Austria; Dr. Frank Stöblen, Diavero Breast Diagnosis Center, Essen, Germany.

\section{References}

1. Arbeitsgemeinschaft für ästhetische, plastische und wiederherstellende Operationsverfahren in der Gynäkologie (AwOGyn) der Deutschen Gesellschaft für Gynäkologie und Geburtshilfe (2008) Sicherheit von Silikon-Brustimplantaten. Available via http:// www.dggg.de/fileadmin/public_docs/Dokumente/Leitlinien/g_01_ 0801 sicherheit silikonbrustimplantaten.pdf. Accessed 7 Oct $20 \overline{0} 9$ 
2. Westdeutsches Brustzentrum: Bechmarking-Berichte. Available via http://www.brustcentrum.de/doc/default.aspx?ID=173\&LID= 996\&CID $=2$. Accessed 7 Oct 2009

3. Sarwer DB, Nordmann JE, Herbert JD (2000) Cosmetic breast augmentation surgery: a critical overview. J Womens Health Gend Based Med 9:843-856

4. Gladfelter J, Murphy D (2008) Breast augmentation motivations and satisfaction: a prospective study of more than 3,000 silicone implantations. Plast Surg Nurs 28:170-174

5. Glynn C, Litherland J (2008) Imaging breast augmentation and reconstruction. Br J Radiol 81:587-595

6. Muir Gray JA (1999) Breast implants: evidence based patient choice and litigation. BMJ 318:414

7. Balzer BL, Weiss SW (2009) Do biomaterials cause implantassociated mesenchymal tumors of the breast? Analysis of eight new cases and review of the literature. Hum Pathol 40:1564-1570

8. Di Benedetto G, Cecchini S, Grassetti L, Baldassarre S, Valeri G, Leva L, Giuseppetti GM, Bertani A (2008) Comparative study of breast implant rupture using mammography, sonography, and magnetic resonance imaging: correlation with surgical findings. Breast J 14:532-537

9. Hauth EA, Hoffmann O, Zadow-Eulerich T, Kimmig R, Forsting M (2008) Die Magnetresonanztomographie in der Diagnostik von Brustimplantaten: Eine Übersicht. Gynäkol Geburtshilfliche Rundsch 48:76-83. doi:10.1159/000118935

10. Koot VCM, Peeters PHM, Granath F, Grobbee DE, Nyren O (2003) Total and cause specific mortality among Swedish women with cosmetic breast implants: prospective study. BMJ 326:527528

11. Handel N (2007) The effect of silicone implants on the diagnosis, prognosis, and treatment of breast cancer. Plast Reconstr Surg 120 (7 Suppl 1):81S-93S

12. Spear SL, Clemens MW, Dayan JH (2008) Considerations of previous augmentation in subsequent breast reconstruction. Aesthet Surg J 28:285-293

13. Rudolph R, Forcier N (2009) Calculation of silicone breast implant volumes using breast magnetic resonance imaging. Aesthet Surg J 29:310-313

14. Robinson OG Jr, Bradley EL, Wilson DS (1995) Analysis of explanted silicone implants: a report of 300 patients. Ann Plast Surg 34:1-6

15. McLaughlin JK, Lipworth L, Murphy DK, Walker PS (2007) The safety of silicone gel-filled breast implants: a review of the epidemiologic evidence. Ann Plast Surg 59:569-580

16. Lloyd C, Hart JL, Niewiarowski S, Lim A, Harvey C, Cosgrove D (2008) Ultrasound in breast imaging. Br J Hosp Med (Lond) 69: M6-M9
17. Making the Best Use of a Department of Cinical Radiology (2007) Guidelines for Doctors, 6th edn. Royal College of Radiologists, London

18. DeMartini W, Lehman C (2008) A review of current evidencebased clinical applications for breast magnetic resonance imaging. Top Magn Reson Imaging 19:143-150

19. Sardanelli F, Giuseppetti GM, Canavese G, Cataliotti L, Corcione S, Cossu E, Federico M, Marotti L, Martincich L, Panizza P, Podo F, Rosselli Del Turco M, Zuiani C, Alfano C, Bazzocchi M, Belli P, Bianchi S, Cilotti A, Calabrese M, Carbonaro L, Cortesi L, Di Maggio C, Del Maschio A, Esseridou A, Fausto A, Gennaro M, Girometti R, Ienzi R, Luini A, Manoukian S, Morassutt S, Morrone D, Nori J, Orlacchio A, Pane F, Panzarola P, Ponzone R, Simonetti G, Torricelli P, Valeri G (2008) Indications for breast magnetic resonance imaging. Consensus document "Attualità in senologia", Florence 2007. Radiol Med 113:1085-1095

20. Hoshaw SJ, Klein PJ, Clark BD, Cook RR, Perkins LL (2001) Breast implants and cancer: causation, delayed detection, and survival. Plast Reconstr Surg 107:1393-1407

21. McIntosh SA, Horgan K (2008) Augmentation mammoplasty: effect on diagnosis of breast cancer. J Plast Reconstr Aesthet Surg 61:124-129

22. Uematsu $T$ (2008) Screening and diagnosis of breast cancer in augmented women. Breast Cancer 15:159-164

23. Esme DL, Bucksch A, Beekman WH (2009) Three-dimensional laser imaging as a valuable tool for specifying changes in breast shape after augmentation mammaplasty. Aesthet Plast Surg 33:191-195

24. Sun SP, Hsu KW, Chen JS (2009) Postoperative evaluation platform of female breast implant surgery with breast configuration indicator. Comput Biol Med 39s:595-603

25. Tepper OM, Karp NS, Small K, Unger J, Rudolph L, Pritchard A, Choi M (2008) Three-dimensional imaging provides valuable clinical data to aid in unilateral tissue expander-implant breast reconstruction. Breast J 14:543-550

26. McCarthy CM, Pusic AL, Kerrigan CL (2008) Silicone breast implants and magnetic resonance imaging screening for rupture: do US Food and Drug Administration recommendations reflect an evidence-based practice approach to patient care? Plast Reconstr Surg 121:1127-1134

27. Kreymerman P, Patrick RJ, Rim A, Djohan R, Crowe JP (2009) Guidelines for using breast magnetic resonance imaging to evaluate implant integrity. Ann Plast Surg 62:355-357

28. U.S. Food and Drug Administration. FDA approves silicone gelfilled breast implants after in-depth evaluation. Available via http:// www.fda.gov/NewsEvents/Newsroom/PressAnnouncements/ 2006/ucm108790.htm. Accessed Dec 8, 2009 